\title{
sciendo
}

\section{Lack of association between TCF7L2 gene variants and type 2 diabetes mellitus in a Brazilian sample of patients with the risk for cardiovascular disease}

\author{
Camile Wunsch ${ }^{1}$, Thais Fernanda Dornelles ${ }^{1}$, Pricila Gir ARdi ${ }^{1}$, Marcelo Emilio ARndT ${ }^{2}$, \\ Julia Pasqualini Genro ${ }^{1,3}$, Veronica Contrini ${ }^{1}$
}

\begin{abstract}
${ }^{1}$ Postgraduate Program in Biotechnology, Universidade do Vale do Taquari - Univates, Lajeado, RS, Brasil; ${ }^{2}$ Hemodynamic Center, Hospital Bruno Born, Lajeado, RS, Brasil; ${ }^{3}$ Postgraduate Program in Biosciences, Universidade Federal de Ciencias da Saude de Porto Alegre, Porto Alegre, RS, Brasil

E-mail:veronica.contini@univates.br
\end{abstract}

Objective. Genetic variants in the transcription factor 7-like 2 (TCF7L2) gene have been described as the most noteworthy ones regarding the type 2 diabetes mellitus (T2DM) liability. This work is aimed to evaluate the association between rs12255372 and rs7903146 polymorphisms and T2DM in patients with cardiovascular disease (CAD) risk.

Methods. A sample of six hundred and forty-seven patients that underwent the coronary angiography in a Cardiac Catheterization Lab was evaluated. The patients were investigated for the presence of T2DM and coronary stenosis. The TCF7L2 polymorphisms were genotyped by realtime PCR and the haplotype analysis was performed with the MLOCUS software. All genetic tests were carried out by considering the haplotype combinations in patients divided into three groups: 0 - carrying none disease risk allele, 1 - carrying one or two risk alleles and 2 - carrying three or four risk alleles.

Results. No significant associations between TCF7L2 risk haplotypes and the presence of T2DM or CAD were detected.

Conclusions. Our results indicate that the TCF7L2 rs12255372 and rs7903146 polymorphisms do not influence T2DM in Brazilian patients with the high risk for CAD. Therefore, we assume that these variants may only be relevant for a specific subgroup of T2DM patients or some particular human population.

Key words: coronary artery disease, risk score, T2DM, CAD, association study

Type 2 diabetes mellitus (T2DM) has a complex etiology, being influenced by a variety of environmental and genetic risk factors (Travers and McCarthy 2011; Szabo et al. 2018). In 2006, the deCode Genetics group linked the 10q chromosome to T2DM, in an investigation of 1185 T2DM Icelandic patients and 931 controls, suggesting a possible effect for variants in the transcription factor 7-like 2 (TCF7L2) gene. Later on, the authors were able to replicate the findings in a Danish cohort and in a US cohort (Grant et al. 2006). Right after, the first genome-wide association study (GWAS) of T2DM, conducted in 1161 Finnish cases and 1174 Finnish controls, confirmed the importance of this gene in the Finnish population (Scott et al. 2007). Since then, many studies have been published, endorsing the strong association be-

Corresponding author: Dr. Veronica Contini, Postgraduate Program in Biotechnology, Universidade do Vale do Taquari Univates, Rua Avelino Talini, 171 - Bairro Universitario, Lajeado, RS - Brasil | CEP 95914-014; phone: 55 (051) 3714 7000, extension 5534; e-mail: veronica.contini@univates.br; ORCID: 0000-0003-2330-7614. 
tween different polymorphisms in the TCF7L2 and $\mathrm{T} 2 \mathrm{DM}$, in a variety of populations (Lyssenko et al. 2007; Chauhan et al. 2010; Long et al. 2012; Turki et al. 2013; Assmann et al. 2014).

$T C F 7 L 2$ gene product is a transcription factor that plays an essential role in the Wnt signaling pathway, acting on the cell proliferation and polarization, embryogenesis, and tissue homeostasis (Weedon 2007; MacDonald et al. 2009). Activation of the Wnt pathway results in $\beta$-catenin binding to one of the TCF/ Lef transcription factors family, for instance, the TCF7L2, leading to the activation of the target genes expression (Jin 2008; Dawson et al. 2013). In vitro and in vivo studies have shown that the Wnt pathway regulates beta pancreatic cell proliferation and acts on insulin secretion. It is also accepted that changes in this pathway can alter the insulin action and resistance, facilitating the T2DM onset (Rulifson et al. 2007; Schinner et al. 2007; Liu and Habener 2008; Palsgaard et al. 2012).

TCF7L2 gene variants, particularly the polymorphisms rs7903146 (C/T) - intron 3 and rs12255372 (G/T) - intron 4, have been described as one of the most significant for the T2DM development (Lyssenko et al. 2007; Tong et al. 2009; Ali 2013). It has been shown that carriers of the rs7903146 risk allele (T-allele) have a decreased insulin secretion when submitted to a glucose tolerance test and higher endogenous glucose production. Moreover, carriers of the $\mathrm{T}$ risk allele, in both polymorphisms (rs7903146 and rs12255372), are known to have higher chances of developing T2DM during their lifetime, when compared to non-carriers of the risk alleles (Lyssenko et al. 2007; Schafer et al. 2007). In post-mortem investigations, a higher level of the TCF7L2 mRNA in pancreatic islets of diabetic patients has been detected, in comparison with the non-diabetic individuals. In addition, a direct correlation between the increased gene expression and the number of copies of the $\mathrm{T}$ allele of the rs7903146 variant, has been identified even in non-diabetic individuals (Lyssenko et al. 2007).

Although there is evidence supporting the importance of TCF7L2 variants in T2DM, it is still controversy, the impact of these polymorphisms in patients with cardiovascular diseases (CVD). CVD are the primary morbidity/mortality causes in T2DM patients, particularly coronary artery disease (CAD), which may two to four times predominate in the diabetic patients (American Diabetes Association 2013). In a study performed on the Brazilian population, it has been detected an association between the $\mathrm{T}$ allele of the rs7903146 polymorphism with a higher frequency of coronary lesions and a more severe clinical presentation of CAD in non-diabetic patients (Sousa et al. 2009). Muendlein and collaborators (2011), have found an association between both rs7903146 e rs12255372 risk alleles and CAD, in an Austrian population sample of diabetic patients. In contrast, other studies did not detect any significant association between TCF7L2 risk alleles and CAD (Bielinski et al. 2008) or T2DM (Barros et al. 2014).

The objective of this study was to evaluate the association between the TCF7L2 rs12255372 (G/T) and rs7903146 (C/T) polymorphisms with $\mathrm{T} 2 \mathrm{DM}$ in a sample of patients with CAD risk.

\section{Materials and methods}

Study design and sample characteristics. The sample was composed of 647 European descent patients (at least 18 years old) that underwent coronary angiography in the Cardiac Catheterization $\mathrm{Lab}(\mathrm{He}-$ modynamic Center of the Hospital Bruno Born), in the Lajeado city, RS, Brazil. Medical professionals referred all the participants to this study through either the Brazilian public health system or private health insurance with at least one of the following conditions: angina pectoris (approximately $70 \%$ of the patients), shortness of the breath, altered electrocardiogram or abnormal laboratory test results. Patients that were unconscious at the time of the examination or unable to understand the study were excluded from the sample group.

All individuals were asked to respond a semistructured questionnaire about their demographic information, family history of cardiovascular disease, alcohol consumption, tobacco use, physical activity, and current medication. Anthropometric data such as weight and height were collected in order to evaluate the body mass index (BMI), calculated by dividing the individual's weight (in kilograms) by the square of height (in meters). Systolic and diastolic arterial blood pressure were measured during the coronary angiography procedure. Also, peripheral blood was collected for biochemical analysis and DNA extraction.

The presence of T2DM was determined according to the American Diabetes Association (2013) diagnostic standards, which considers patients with a fasting glucose blood level $\leq 126 \mathrm{mg} / \mathrm{dl}$ to be diabetics. All participants were also classified in a global risk score (GRS) for the development of CAD, according to the Brazilian guideline on dyslipidemia and atherosclerosis prevention (Xavier et al. 2013). The GRS considered the following variables: sex, age, total cholesterol levels, high-density lipoprotein cho- 
lesterol (HDL-c) levels, systemic arterial pressure, treated and untreated, tobacco use, and T2DM diagnosis. According to the GRS, patients were ranked as low, intermediate or high risk for CAD development. CAD diagnosis was evaluated by a cardiologist after considering the coronary angiography reports of the patients. The individuals were classified as cases if at least one significant coronary artery stenosis wider than $50 \%$ of the luminal diameter was present. Individuals with a coronary artery occlusion less than or equal to $50 \%$ of the luminal diameter were considered as the control group.

The Research Ethical Committee of the Universidade do Vale do Taquari - Univates (COEP/UNIVATES), resolution 466/2012, approved this study. All participants of this study signed an informed consent form.

Biochemical analysis. The biochemical parameters, fasting glucose, total cholesterol, HDL-c, and triglycerides levels, were determined by the colorimetric method with commercial kits (BioClin $\%$ Quibasa, Brazil) in the automated BS-120 system (Mindray ${ }^{\circledast}$ DS, USA, Inc). We confirmed the quality of the measurements using commercial normal and pathologic controls from BioClin ${ }^{\circledast}$. All patients had a 12-hour fasting period before blood sample collection.

Molecular analyses. We performed DNA extraction using the salting out procedure, described by Lahiri and Nurnberger (1991), and the samples were quantified by spectrophotometric optical density, in an L-Quant ${ }^{\oplus}$ equipment. For subsequent assays, all DNA samples were normalized to $20 \mathrm{ng} / \mu \mathrm{l}$. The polymorphisms were genotyped by TaqMan Allelic Discrimination Assays (Thermo Fisher Scientific Inc.), in a StepOnePlus ${ }^{\circledast}$ real-time PCR system (Thermo Fisher Scientific Inc), according to the manufacturer's protocols. TaqMan assay codes were C_291484_20 for the rs12255372 and C_29347861_10 for the rs7903146.

Statistical analyses. Allele frequencies were obtained by direct counting and the Hardy-Weinberg equilibrium, for genotype frequencies, was tested with the chi-squared test. The MLOCUS software was used to estimate linkage disequilibrium and haplotype frequencies for the rs12255372 and rs7903146 polymorphisms. All genetic analyses were performed considering the formed haplotypes. The patients were grouped and represented as: 0 - carrying none disease risk allele ( $\mathrm{T}$, for both variants); 1 - carrying one or two risk alleles and 2 - carrying three or four risk alleles. Statistical analysis was performed using the SPSS (Statistical Package for Social Sciences) software version 21.0. Genetic effects in continuous clinical variables were tested by analysis of variance, for variables with normal distribution or by the corresponding non-parametric test (Kruskal-Wallis), for non-normal distribution variables. The chi-square test tested the association between the haplotypes and the categorical variables.

\section{Results}

The present study evaluated 647 individuals who were predominately males (58\%) with an average age of $62.7 \pm 10.89$ years. From the total number of individuals, $145(22.4 \%)$ were classified as diabetic patients, 439 (67.8\%) presented a high risk of the cardiovascular disease, according to the GRS, and 355 (55\%) had a coronary stenosis diagnosed. The clinical and demographic characterizations of the sample are shown in Table 1.

Allele and genotype frequencies of the rs 12255372 and rs7903146 polymorphisms are shown in Table 2.

Table 1

Demographic and clinical characterization of the sample

\begin{tabular}{|c|c|}
\hline Characteristic & $\begin{array}{l}\text { Patients } \\
(\mathrm{n}=647)\end{array}$ \\
\hline Age (years) & $62.70(10.89)$ \\
\hline Years of school ${ }^{a}$ & $5.0(4.0)$ \\
\hline Sex (male) & $375(58.0)$ \\
\hline Smoking (yes) & $88(13.6)$ \\
\hline Alcohol use (yes) & $195(30.1)$ \\
\hline $\operatorname{BMI}\left(\mathrm{kg} / \mathrm{m}^{2}\right)$ & $27.74(4.88)$ \\
\hline \multicolumn{2}{|l|}{ Blood Pressure } \\
\hline Systolic (mmHg) & $142.39(24.24)$ \\
\hline Diastolic (mmHg) & $77.38(10.22)$ \\
\hline \multicolumn{2}{|l|}{ Clinical History } \\
\hline Diagnosis of CAD & $355(55.0)$ \\
\hline Diagnosis of T2DM & $145(22.4)$ \\
\hline \multicolumn{2}{|l|}{ Cardiovascular Risk Score } \\
\hline Low & $40(6.2)$ \\
\hline Intermediate & $168(26.0)$ \\
\hline High & $439(67.8)$ \\
\hline \multicolumn{2}{|l|}{ Biochemical parameters } \\
\hline Fasting blood glucose $(\mathrm{mmol} / \mathrm{l})^{\mathrm{a}}$ & $5.49(1.39)$ \\
\hline Total cholesterol $(\mathrm{mmol} / \mathrm{l})$ & $4.21(1.27)$ \\
\hline HDL cholesterol $(\mathrm{mmol} / \mathrm{l})^{\mathrm{a}}$ & $1.03(0.46)$ \\
\hline Triglycerides $(\mathrm{mmol} / \mathrm{l})^{\mathrm{a}}$ & $1.14(0.85)$ \\
\hline
\end{tabular}

Abbreviations: BMI - body mass index; CAD - coronary artery disease; T2DM - type 2 diabetes mellitus. Data are presented as mean and (standard deviation) or $\mathrm{n}$ and (\%). ${ }^{\mathrm{a}}$ Median and (interquartile range). 
Table 2

Genotype, allele, haplotype, and diplotype frequencies of the TCF7L2 polymorphisms in the total sample

\begin{tabular}{|c|c|}
\hline Polymorphism & Frequency \\
\hline \multicolumn{2}{|l|}{ rs12255372 } \\
\hline GG & $305(47.1)$ \\
\hline GT & $277(42.8)$ \\
\hline TT & $65(10.1)$ \\
\hline Allele G & 0.69 \\
\hline Allele T & 0.31 \\
\hline \multicolumn{2}{|l|}{ rs7903146 } \\
\hline $\mathrm{CC}$ & $298(46.1)$ \\
\hline CT & $279(43.1)$ \\
\hline TT & $70(10.8)$ \\
\hline Allele C & 0.68 \\
\hline Allele T & 0.32 \\
\hline \multicolumn{2}{|l|}{$\begin{array}{l}\text { Haplotype } \\
\text { (rs122555371/rs7903146) }\end{array}$} \\
\hline Haplotype GC & 0.633 \\
\hline Haplotype GT & 0.053 \\
\hline Haplotype TC & 0.043 \\
\hline Haplotype TT & 0.271 \\
\hline \multicolumn{2}{|l|}{ Diplotypes } \\
\hline GC/GC & $261(40.3)$ \\
\hline GC/TT & $226(34.9)$ \\
\hline GC/GT & $39(6.0)$ \\
\hline GC/TC & $36(5.6)$ \\
\hline TT/TT & $48(7.4)$ \\
\hline GT/TT & $16(2.5)$ \\
\hline GT/GT & $5(0.8)$ \\
\hline $\mathrm{TC} / \mathrm{TT}$ & $15(2.3)$ \\
\hline TC/TC & $1(0.2)$ \\
\hline
\end{tabular}

Genotypes and diplotypes are expressed as $\mathrm{n}$ and (\%). Alleles and haplotypes are expressed in absolute frequencies.

Genotype frequencies in both polymorphisms are in accordance with the Hardy-Weinberg equilibrium. Haplotype analysis revealed that the TCF7L2 variants investigated in this study are in linkage disequilibrium $\left(\mathrm{D}^{\prime}=0.80\right)(\mathrm{p}<0.001)$. The haplotype and diplotype frequencies are also shown in Table 2.

No significant associations between the TCF7L2 haplotypes with the presence of T2DM $(\mathrm{p}=0.46)$ or with blood glucose levels (all patients, $\mathrm{p}=0.42$; T2DM patients, $\mathrm{p}=0.43)$ were detected. Likewise, the haplotypes did not influence the presence of coronary stenosis $(\mathrm{p}=0.92)$ or the classification in the GRS for CAD development ( $\mathrm{p}=0.77$ ) (Table 3$)$.

\section{Discussion}

Our findings suggest that there is no significant association between the TCF7L2 rs7903146 and rs12255372 polymorphisms and T2DM in Brazilian individuals studied. Besides, we did not detect any significant genetic effect on the fasting glucose levels of the patients. Our results diverge from most of the published studies to date that investigated the role of the TCF7L2 polymorphisms in the same variables (Cauchi et al. 2007; Lyssenko et al. 2007; Tong et al. 2009; Muendlein et al. 2011; Wang et al. 2013). On the other hand, our findings are consistent with two studies also conducted on Brazilian samples, which evaluated rs7903146 and rs12255372 polymorphisms in individuals with T2DM (Barros et al. 2014) and in women with gestational diabetes (de Melo et al. 2015). Furthermore, it is important to remark that in the present study, T2DM was evaluated in a sample of patients undergoing coronary angiography, most of them with a high cardiovascular risk according to the GRS for CAD development. It is plausible that different susceptibility variants are acting upon patients that have isolated T2DM or patients having T2DM associated with other diseases, like the patients from our sample group.

Regarding CAD, we also did not find any significant association between the investigated polymorphisms with the presence of coronary stenosis or with the GRS for CAD development. The probable effect of those variants in coronary findings was not well elucidated yet, being reported in the current literature as controversial data. Our results are in agreement with Bielinski and collaborators (2008), who did not find associations between CAD and the risk alleles of the TCF7L2. However, it is important to highlight the sample design differences, since Bielinski et al. (2008) have evaluated individuals from the Atherosclerosis Risk in Communities (ARIC) project, which had no previous cardiovascular disease manifestations at the beginning of the study. In our sample, recruited in a Catheterization Lab, the patients had already a suspect CAD or were pre-diagnosed with it. In the Brazilian population, Marquezine and collaborators (2008) have detected an association between the rs7903146 $\mathrm{T}$ allele and an increased risk of T2DM onset in CAD patients. However, in their sample, the allelic frequencies observed $(\mathrm{C}=0.58$ and $\mathrm{T}=0.42$ ) are very different from that found in our study ( $\mathrm{C}=0.68$ and $\mathrm{T}=0.32)$, as well as what that 
Table 3

Association between clinical characteristics of the sample and the TCF7L2 haplotypes

\begin{tabular}{|c|c|c|c|c|}
\hline \multirow{2}{*}{ Characteristic } & \multicolumn{3}{|c|}{ Haplotypes TCF7L2 } & \multirow{2}{*}{ p-value } \\
\hline & $0(n=261)$ & $1(n=307)$ & $2(n=79)$ & \\
\hline Diagnosis of CAD & $146(55.9)$ & $166(54.1)$ & $43(54.4)$ & 0.92 \\
\hline Diagnosis of T2DM & $53(20.3)$ & $71(23.1)$ & $21(26.6)$ & 0.46 \\
\hline \multicolumn{5}{|l|}{ Cardiovascular Risk } \\
\hline Low & $16(6.1)$ & $18(5.9)$ & $6(7.6)$ & 0.77 \\
\hline Intermediate & $65(24.9)$ & $86(28.0)$ & $17(21.5)$ & \\
\hline High & $180(69.0)$ & $203(66.1)$ & $56(70.9)$ & \\
\hline \multicolumn{5}{|l|}{ Biochemical parameters } \\
\hline Fasting blood glucose (mmol/l) (all patients) & $5.44(1.33)$ & $5.55(1.33)$ & $5.49(1.17)$ & 0.42 \\
\hline Fasting blood glucose (mmol/l) (T2DM patients) & $7.94(4.94)$ & $7.55(2.33)$ & $8.38(4.11)$ & 0.43 \\
\hline
\end{tabular}

Abbreviations: CAD - coronary artery disease; T2DM - type 2 diabetes mellitus. Data are presented as $\mathrm{n}$ and (\%) or median and (interquartile range). Haplotype groups: $0=\mathrm{GC} / \mathrm{GC} ; 1=\mathrm{GC} / \mathrm{TT}+\mathrm{GC} / \mathrm{GT}+\mathrm{GC} / \mathrm{TC}+\mathrm{GT} / \mathrm{GT}+\mathrm{TC} / \mathrm{TC} ; 2=\mathrm{GT} / \mathrm{TT}+\mathrm{TC} / \mathrm{TT}+$ TT+TT.

which is predicted for the European population $(\mathrm{C}=0.72$ and $\mathrm{T}=0.28)$ (NCBI 2017). In this context, it is possible to assume that although both studies have a similar clinical design the two populations may be genetically different, suggesting that factors like allele, and/or genetic heterogeneity may play a role in the onset of T2DM in CAD patients. In other study performed by the same research group, at this time with two independent patient groups with cardiovascular disease, an effect of rs7903146 variant only in non-diabetic patients has been shown. Carriers of the $\mathrm{T}$ allele had a higher incidence of coronary lesions, with a more severe CAD onset and affecting multiple blood vessels, when compared to non-diabetic patients carrying the CC genotype (Sousa et al. 2009). In a different study performed on an Austrian population, associations of both rs7903146 and rs12255372 polymorphisms with CAD and T2DM has been detected, but the effect was not observed in non-diabetic patients (Muendlein et al. 2011).

Altogether, our findings agree with the concept that multifactorial diseases, like T2DM and CAD, are highly complex and reinforce the need to perform studies in different populations, especially considering the literature evidence of some population-specific genetic risk variants (Szabo et al. 2018). In this scenario, it is relevant to show negative findings since they could be incorporated in future meta-analysis studies to clarify the role of TCF7L2 variants in these disorders. Although more than 150 genetic variants have already been associated with T2DM development, these variants account for only a small portion of the heritability of the disease, suggesting that factors such as gene-gene or gene-environment interacts has to be taken into account (Szabo et al. 2018). Therefore, considering our results, it is reasonable to assume that TCF7L2 variants investigated here are only relevant for a specific subgroup of T2DM patients or in some particular population.

Finally, this study needs to be understood with considering certain limitations: first, the lack of the insulin secretion measurement; second, the absence of the glycosylated hemoglobin test, which would reinforce the T2DM diagnostic in our patient group; third, the relatively small number of patients used with diabetes; and fourth, the absence of the degree of coronary stenosis evaluation, in the CAD patients.

\section{Acknowledgements}

The authors thank the Servico de Hemodinamica (Cardiac Catheterization Lab) from the Hospital Bruno Born for the help in the sample collection and the Fundacao Vale do Taquari de Educacao e Desenvolvimento Social (FUVATES) for the financial support.

\section{References}

Ali O. Genetics of type 2 diabetes. World J Diabetes 4,114-123, 2013.

American Diabetes Association. Diagnosis and classification of diabetes mellitus. Diabetes Care 36, S67-S74, 2013. 
Assmann TS, Duarte GCK, Rheinheimer J, Cruz LA, Canani LH and Crispim D. The TCF7L2 rs7903146 (C/T) polymorphism is associated with risk to type 2 diabetes mellitus in Southern-Brazil. Arq Bras Endocrinol Metabol 58, 918-925, 2014.

Barros CMAR, Araujo-Neto AP, Lopes TR, Barros MAL, Motta FJN, Canalle R, Nunes LCC, Rey JA, Burbano RR, Lima-Barros MA, Yoshioka FK, Pinto GR. Association of the rs7903146 and rs12255372 polymorphisms in the TCF7L2 gene with type 2 diabetes in a population from northeastern Brazil. Genet Mol Res 13, 78897898, 2014.

Bielinski SJ, Pankow JS, Folsom AR, North KE and Boerwinkle E. TCF7L2 single nucleotide polymorphisms, cardiovascular disease and all-cause mortality: the Atherosclerosis Risk in Communities (ARIC) study. Diabetologia 51, 968-970, 2008.

Cauchi S, El Achhab Y, Choquet H, Dina C, Krempler F, Weitgasser R, Nejjari C, Patsch W, Chikri M, Meyre D, Froguel P. TCF7L2 is reproducibly associated with type 2 diabetes in various ethnic groups: a global metaanalysis. J Mol Med 85, 777-782, 2007.

Chauhan G, Spurgeon CJ, Tabassum R, Bhaskar S, Kulkarni SR, Mahajan A, Chavali S, Kumar MV, Prakash S, Dwivedi OP, Ghosh S, Yajnik CS, Tandon N, Bharadwaj D, Chandak GR. Impact of common variants of PPARG, KCNJ11, TCF7L2, SLC30A8, HHEX, CDKN2A, IGF2BP2, and CDKAL1 on the risk of type 2 diabetes in 5,164 Indians. Diabetes 59, 2068-2074, 2010.

Dawson K, Aflaki M, Nattel S. Role of the Wnt-Frizzled system in cardiac pathophysiology: a rapidly developing, poorly understood area with enormous potential. J Physiol 591, 1409-1432, 2013.

de Melo SF, Frigeri HR, dos Santos-Weiss ICR, Rea RR, de Souza EM, Alberton D, Gomes de Moraes Rego F, Picheth G. Polymorphisms in FTO and TCF7L2 genes of Euro-Brazilian women with gestational diabetes. Clin Biochem 48, 1064-1067, 2015.

Grant SF, Thorleifsson G, Reynisdottir I, Benediktsson R, Manolescu A, Sainz J, Helgason A, Stefansson H, Emilsson V, Helgadottir A, Styrkarsdottir U, Magnusson KP, Walters GB, Palsdottir E, Jonsdottir T, Gudmundsdottir T, Gylfason A, Saemundsdottir J, Wilensky RL, Reilly MP, Rader DJ, Bagger Y, Christiansen C, Gudnason V, Sigurdsson G, Thorsteinsdottir U, Gulcher JR, Kong A, Stefansson K. Variant of transcription factor 7-like 2 (TCF7L2) gene confers risk of type 2 diabetes. Nat Genet 38, 320-323, 2006.

Jin T. The WNT signalling pathway and diabetes mellitus. Diabetologia 51, 1771-1780, 2008.

Lahiri DK, Nurnberger JI Jr. A rapid non-enzymatic method for the preparation of HMW DNA from blood for RFLP studies. Nucleic Acids Res 19, 5444, 1991.

Liu Z, Habener JF. Glucagon-like peptide-1 activation of TCF7L2-dependent Wnt signaling enhances pancreatic beta cell proliferation. J Biol Chem 283, 8723-8735, 2008.

Long J, Edwards T, Signorello LB, Cai Q, Zheng W, Shu XO, Blot WJ. Evaluation of genome-wide association studyidentified type 2 diabetes loci in African Americans. Am J Epidemiol 176, 995-1001, 2012.

Lyssenko V, Lupi R, Marchetti P, Del Guerra S, Orho-Melander M, Almgren P, Sjogren M, Ling C, Eriksson KF, Lethagen AL, Mancarella R, Berglund G, Tuomi T, Nilsson P, Del Prato S, Groop L. Mechanisms by which common variants in the TCF7L2 gene increase risk of type 2 diabetes. J Clin Invest 117, 2155-2163, 2007.

MacDonald BT, Tamai K, He X. Wnt/beta-catenin signaling: components, mechanisms, and diseases. Dev Cell 17, 9-26, 2009.

Marquezine G, Pereira A, Sousa A, Mill J, Hueb W, Krieger J. TCF7L2 variant genotypes and type 2 diabetes risk in Brazil: significant association, but not a significant tool for risk stratification in the general population. BMC Med Genet 9, 106, 2008.

Muendlein A, Saely CH, Geller-Rhomberg S, Sonderegger G, Rein P, Winder T, Beer S, Vonbank A, Drexel H. Single nucleotide polymorphisms of TCF7L2 are linked to diabetic coronary atherosclerosis. PLoS One 6, el7978, 2011.

Palsgaard J, Emanuelli B, Winnay JN, Sumara G, Karsenty G, Kahn CR. Cross-talk between insulin and Wnt signaling in preadipocytes: role of Wnt co-receptor low density lipoprotein receptor-related protein-5 (LRP5). J Biol Chem 287, 12016-12026, 2012.

Rulifson IC, Karnik SK, Heiser PW, ten Berge D, Chen H, Gu X, Taketo MM, Nusse R, Hebrok M, Kim SK. Wnt signaling regulates pancreatic beta cell proliferation. Proc Natl Acad Sci 104, 6247-6252, 2007.

Schafer SA, Tschritter O, Machicao F, Thamer C, Stefan N, Gallwitz B, Holst JJ, Dekker JM, 't Hart LM, Nijpels G, van Haeften TW, Haring HU, Fritsche A. Impaired glucagon-like peptide-1-induced insulin secretion in carriers of transcription factor 7-like 2 (TCF7L2) gene polymorphisms. Diabetologia 50, 2443-2450, 2007.

Schinner S, Ulgen F, Papewalis C, Schott M, Woelk A, Vidal-Puig A, Scherbaum WA. Regulation of insulin secretion, glucokinase gene transcription and beta cell proliferation by adipocyte-derived Wnt signalling molecules. Diabetologia 51, 147-154, 2007. 
Scott LJ, Mohlke KL, Bonnycastle LL, Willer CJ, Li Y, Duren WL, Erdos MR, Stringham HM, Chines PS, Jackson AU, Prokunina-Olsson L, Ding CJ, Swift AJ, Narisu N, Hu T, Pruim R, Xiao R, Li XY, Conneely KN, Riebow NL, Sprau AG, Tong M, White PP, Hetrick KN, Barnhart MW, Bark CW, Goldstein JL, Watkins L, Xiang F, Saramies J, Buchanan TA, Watanabe RM, Valle TT, Kinnunen L, Abecasis GR, Pugh EW, Doheny KF, Bergman RN, Tuomilehto J, Collins FS, Boehnke M. A genome-wide association study of type 2 diabetes in Finns detects multiple susceptibility variants. Science 316, 1341-1345, 2007.

Sousa AGP, Marquezine GF, Lemos PA, Martinez E, Lopes N, Hueb WA, Krieger JE, Pereira AC. TCF7L2 polymorphism rs7903146 is associated with coronary artery disease severity and mortality. PLoS One 4, e7697, 2009.

Szabo M, Mate B, Csep K, Benedek T. Genetic approaches to the study of gene variants and their impact on the pathophysiology of type 2 diabetes. Biochem Genet 56, 22-55, 2018.

Tong Y, Lin Y, Zhang Y, Yang J, Zhang Y, Liu H, Zhang B. Association between TCF7L2 gene polymorphisms and susceptibility to type 2 diabetes mellitus: a large Human Genome Epidemiology (HuGE) review and metaanalysis. BMC Med Genet 10, 15, 2009.

Travers ME, McCarthy MI. Type 2 diabetes and obesity: genomics and the clinic. Hum Genet 130, 41-58, 2011.

Turki A, Al-Zaben GS, Mtiraoui N, Marmmuoch H, Mahjoub T, Almawi WY. Transcription factor-7-like 2 gene variants are strongly associated with type 2 diabetes in Tunisian Arab subjects. Gene 513, 244-248, 2013.

Wang J, Zhang J, Li L, Wang Y, Wang Q, Zhai Y, You H, Hu D. Association of rs12255372 in the TCF7L2 gene with type 2 diabetes mellitus: a meta-analysis. Brazilian J Med Biol Res 46, 382-393, 2013.

Weedon MN. The importance of TCF7L2. Diabet Med 24, 1062-1066, 2007.

Xavier HT, Izar MC, Faria Neto JR, Assad MH, Rocha VZ, Sposito AC, Fonseca FA, Santos JE dos, Santos RD, Bertolami MC, Faludi AA, Martinez TLR, Diament J, Guimaraes A, Forti NA, Moriguchi E, Chagas ACP, Coelho OR, Ramires JAF. V Diretriz Brasileira de Dislipidemias e Prevencao da Aterosclerose. Arq Bras Cardiol 101, 1-22, 2013. 